\title{
Article \\ Characteristic and Attribution of Runoff Variation in the Yanhe River Basin, Loess Plateau, Based on the Budyko Hypothesis
}

\author{
Kun Hou ${ }^{1} \mathbb{C}$, Jiping Wang ${ }^{2}$ and Xiuru Wang ${ }^{1, *}$ \\ 1 School of Soil and Water Conservation, Beijing Forestry University, Beijing 100083, China; \\ houkun0822@163.com \\ 2 Research Center of Saline and Alkali Land of State Forestry Administration, Chinese Academy of Forestry, \\ Beijing 100091, China; wjp_gis@163.com \\ * Correspondence: wang-xr@163.com; Tel.: +86-10-6233-8044
}

Citation: Hou, K.; Wang, J.; Wang, X. Characteristic and Attribution of Runoff Variation in the Yanhe River Basin, Loess Plateau, Based on the Budyko Hypothesis. Water 2022, 14, 495. https://doi.org/10.3390/ w14030495

Academic Editors: Alban Kuriqi and Luis Garrote

Received: 22 December 2021

Accepted: 5 February 2022

Published: 7 February 2022

Publisher's Note: MDPI stays neutral with regard to jurisdictional claims in published maps and institutional affiliations.

Copyright: (c) 2022 by the authors. Licensee MDPI, Basel, Switzerland. This article is an open access article distributed under the terms and conditions of the Creative Commons Attribution (CC BY) license (https:// creativecommons.org/licenses/by/ $4.0 /)$.

\begin{abstract}
The ecological restoration projects in the Loess Plateau (LP) has significantly altered the underlying surface conditions, coupled with a warming-wetting climate, which has profoundly affected the regional water cycle. Evaluating the response of runoff to external environmental change and quantitatively identifying the contribution of anthropogenic interference and climate change are prerequisites for efficient utilization of water resources in arid/semi-arid regions. Daily recorded data of hydrological and meteorological elements between 1969 and 2019 and the elasticity coefficient method based on Budyko hypothesis were used for attribution analysis of runoff change in the Yanhe River basin. The results show the following: (1) the measured runoff decreased significantly $\left(p<0.05,-0.2845 \mathrm{~mm}\right.$ year $\left.^{-1}\right)$, and suggested substantial difference before and after 2000; (2) the area of woodland and grassland had a sharp increase from 2000, while the elasticity of runoff to precipitation, potential evapotranspiration $\left(E T_{0}\right)$, and vegetation all decreased; (3) the improvement of underlying surface conditions has become the leading factor of runoff reduction with a contribution of $96.78 \%$; (4) the impact of vegetation restoration on runoff reduction is effective within a certain threshold. We consider that more attention should be paid to the afforestation scale and its possible negative eco-hydrological effects in future ecological restoration.
\end{abstract}

Keywords: Loess Plateau; anthropogenic disturbance; runoff; elasticity coefficient; Budyko hypothesis; warming-wetting

\section{Introduction}

A changing environment strongly influenced by climate and anthropogenic interference can directly affect the land surface process [1] and alter the mechanism of runoff generation and concentration [2]. Decreasing trends in runoff and sediment loads have been observed in approximately $50 \%$ of the world's rivers, due to the effects of climate change, when coupled with the impacts of other natural and anthropogenic disturbances [3]. The middle reaches of the Yellow River (YR) in China, which is located in an arid/semi-arid region, have undergone particularly profound declines in runoff, and have gradually become areas of considerable research [4]. Moreover, the sharp reduction of runoff has led to new problems such as the serious shrinkage of the channel in the lower reaches and the reduction of the flood capacity [5].

As one of the common concerns in the field of global water cycle research, runoff dynamic change is particularly sensitive to climate [6,7]. The variation of meteorological elements such as precipitation, temperature, wind speed, and radiation change the cycle and distribution of water resources, and then affect river runoff [8]. China has experienced significant climate change, with the warmest 20 years since the 20th century. Studies have found that the temperature and precipitation have increased in the past 10-15 years in northwest China, exhibiting a trend of warming-wetting $[9,10]$. In particular, the temperature in the source of the YR [11] and part of the LP [12], showed a faster increase than the 
average level for China and the world. The ecological environment and human lives may be adversely affected by extreme climate. Extreme temperature events may lead to glacier melting, reducing ice and snow reserves located upstream, then weakening the ability of glaciers to recharge runoff [13]. Extreme precipitation events may result in infiltrationexcess runoff production, causing surface scour and then destroying vegetation roots.

As another important factor, human activities affect hydrological processes mainly through the construction of water conservancy projects [14], the change of underlying surface caused by vegetation restoration [15], etc. Vegetation is an important part of the terrestrial ecosystem and also the most sensitive component of climate change. Since 1999, because of the implementation of ecological restoration projects such as the Grain for Green Project (GGP), the vegetation coverage in arid/semi-arid areas of northwest China has been significantly improved [16], having a profound impact on the underlying surface conditions and hydrological processes in the YR basin. Some scholars believe that the ecological restoration measures have played an absolute leading role in the reduction of runoff and sediment loads in the YR basin $[17,18]$. However, due to the diversity of the ecosystem, the resources required by vegetation growth cannot be met without limit, while the impact of ecological restoration measures on hydrological processes depends on the scale and coverage of vegetation.

At present, monitoring vegetation dynamics and quantifying the response of vegetation growth to climate has become an important field of global change research in the context of frequent extreme climate events $[19,20]$. Some scholars have studied the correlation between normalized difference vegetation index (NDVI) variation characteristics of different vegetation types and climate factors at different scales. The results showed that vegetation growth was very sensitive to temperature and precipitation, and climate change has a significant impact on vegetation growth [21], especially in arid/semi-arid areas [22], where extreme climate leads to a decrease in vegetation coverage. In recent years, under the background of large-scale vegetation restoration, have the changes of climate and underlying surface conditions had new effects on runoff in the Loess hilly-gully region with complex geographical conditions? How does the passive remodeling process of hydrological connectivity caused by dramatic changes in underlying surface, affect runoff? The revelation of these concerns will be beneficial in understanding the geographical differentiation of the hydrological effects caused by vegetation and climate change.

Several methods have been applied to quantitatively distinguish the impact of climate and anthropogenic disturbance on runoff, such as the hydrological model [23], the elasticity coefficient [24], the watershed comparative analysis [25], etc. Among them, the elasticity coefficient, based on the Budyko hypothesis, has been widely used in the study of the law of runoff variation, due to its good performance in distinguishing the sensitivity and contribution of the potential factors. For half a century, many scholars have carried out theoretical derivation and empirical research on the Budyko empirical model [26,27].Current studies mainly tend to modify the control parameters in the empirical model, and some research conclusions directly attribute the coupling parameters of precipitation and temperature to the contribution of the underlying surface [28].The research results obtained by using this method have also been widely reported. Zheng et al. [29] analyzed runoff variability in the alpine region (source of the YR) by using the elasticity coefficient method, and found that the contribution of land-use and climate to runoff change were $70 \%$ and $30 \%$, respectively. Liu et al. [30] analyzed the variation of the streamflow in a water diversion project in the semi-humid region by using six different elasticity coefficient models based on the Budyko hypothesis, and found that climate change was the main factor leading to the decline of streamflow, contributing 84.1-90.1\%. Li et al. [4] analyzed runoff changes in 12 semi-arid basins (the middle reaches of the YR), based on the Choudhury-Yang model and the elastic coefficient, and found that vegetation was the leading factor of runoff decline. However, under the background of climate fluctuation and frequent extreme climate, the application of the Budyko model in the attribution analysis of runoff change in the ecologically fragile 
Loess hilly-gully region requires further consideration of the specific conditions of the underlying surface of the study area.

Above all, it is of theoretical and practical significance to quantitatively distinguish the effects of anthropogenic disturbance and climate variation on runoff, so as to deeply appreciate the process of water cycle and improve the management measures of water resources. The main objectives of this paper are to (1) investigate the trends of the main hydrological and meteorological elements in the Yanhe River basin from 1969 to 2019, and study the substantial difference before and after the change point; (2) analyze the transfer of land-use structure caused by the GGP; (3) calculate the elasticity of runoff to precipitation, $E T_{0}$, and vegetation; and (4) distinguish the contributions of the above factors to the variation of runoff. This study is structured as follows: In Section 2, the study area, data sources, and methods used in our study are introduced in detail. In Section 3, the trend and elasticity of runoff are evaluated, the land-use transfer processes are identified, and the contributions of climate and anthropogenic interference are calculated. In Section 4, the eco-hydrological effect of vegetation restoration and the uncertainty in attribution analysis of runoff change are discussed. The conclusions are proposed in the final section.

\section{Materials and Methods}

\subsection{Basic Data}

This study primarily focuses on the area above the control section of the Ganguyi Hydrological Station in the Yanhe River basin, encompassing an area of $5891.64 \mathrm{~km}^{2}$ (Figure 1), with a relative altitude difference of $972 \mathrm{~m}$. From 1969 to 2019, the annual average precipitation was $489.79 \mathrm{~mm}$, the maximum precipitation was $844.60 \mathrm{~mm}$, and the minimum was $296.46 \mathrm{~mm}$. The annual precipitation distribution was mostly concentrated in the flood season (from June to September), accounting for more than $70 \%$ of the total annual precipitation. The annual average temperature was $9.4{ }^{\circ} \mathrm{C}$, the annual average wind speed was $1.3-3.3 \mathrm{~m} \mathrm{~s}^{-1}$, the annual average sunshine was $2418 \mathrm{~h}$, the accumulated $\geq 0{ }^{\circ} \mathrm{C}$ annual total temperature was $3878.1{ }^{\circ} \mathrm{C}$, the annual average frost-free period was 172 days, and the annual average evaporation was about $1000 \mathrm{~mm}$.

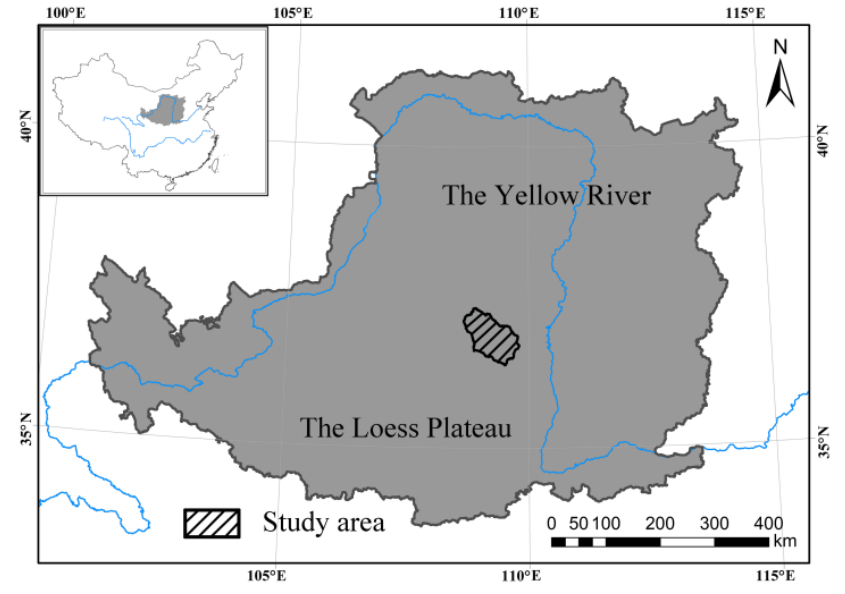

(a)

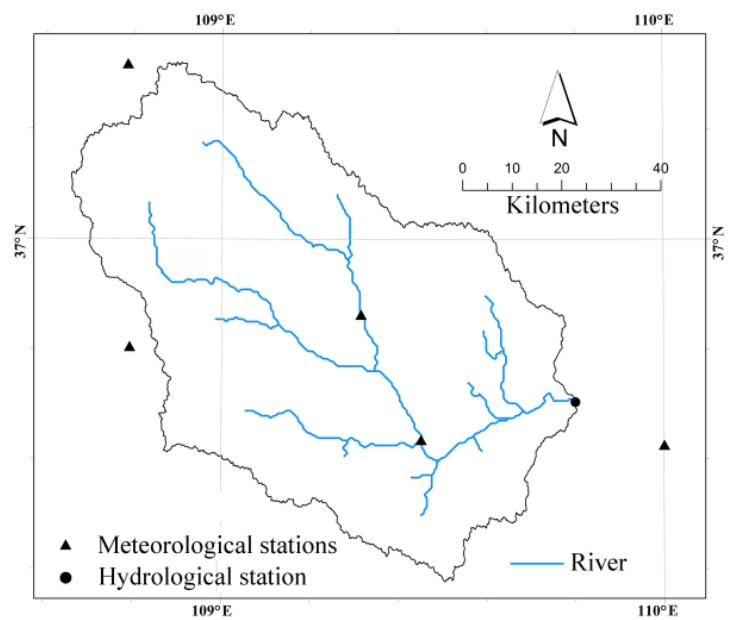

(b)

Figure 1. Location of the study area: (a) location of Yanhe River Basin on the Loess Plateau, (b) distribution of hydrological and weather stations.

The daily measured runoff data used in the paper were recorded by the Ganguyi Hydrological Station in the middle reaches of the YR. The meteorological records, such as precipitation, temperature, etc., were obtained from five stations: Ansai, Jingbian, Yan'an, Yanchang, and Zhidan. 
Land-use changes were determined using remote sensing images from 1985, 1995, 2000, 2008, and 2015 (resolution $30 \mathrm{~m} \times 30 \mathrm{~m}$ ). Land-use was mapped by conducting supervised classifications on the images and through manual visual interpretations, using ERDAS 9.2 and ArcGIS 10.2 software.

\subsection{Data Processing and Analysis}

\subsubsection{Potential Evapotranspiration}

The $E T_{0}$ was calculated according to the following equation [31]:

$$
E T_{0}=\frac{0.408 \Delta\left(R_{n}-G\right)+\gamma \frac{900}{T_{\alpha}+273} u_{2} V P D}{\Delta+\gamma\left(1+0.34 u_{2}\right)}
$$

where $E T_{0}$ is the daily potential evapotranspiration $\left(\mathrm{mm} \cdot \mathrm{d}^{-1}\right), \Delta$ is the slope of saturated vapor pressure in relation to air temperature $\left(\mathrm{kPa} \cdot{ }^{\circ} \mathrm{C}^{-1}\right), R_{n}$ is the net radiation at the canopy surface $\left(\mathrm{MJ} \cdot \mathrm{m}^{-2} \cdot \mathrm{d}^{-1}\right), \mathrm{G}$ is the soil heat flux density $\left(\mathrm{MJ} \cdot \mathrm{m}^{-2} \cdot \mathrm{d}^{-1}\right), \gamma$ is the psychrometric constant $\left(\mathrm{kPa} \cdot{ }^{\circ} \mathrm{C}^{-1}\right), \mathrm{T}_{\alpha}$ is the mean daily air temperature at $2 \mathrm{~m}$ height $\left({ }^{\circ} \mathrm{C}\right)$, $u_{2}$ is the wind speed at $2 \mathrm{~m}$ height $\left(\mathrm{m} \cdot \mathrm{s}^{-1}\right), \mathrm{VPD}$ is the vapor pressure deficit $(\mathrm{kPa})$. The annual $E T_{0}$ was obtained by the accumulative daily values.

\subsubsection{Time-Varying Trends in Hydrological and Meteorological Elements}

The daily measured runoff (calculated by dividing the total annual volume of stream flow by the upstream basin area, $\mathrm{mm}$ ), precipitation, and $E T_{0}$ data were collected, sorted and counted on an annual basis from 1969 to 2019. The Mann-Kendall (MK) method [32,33] and a double mass curve were also applied to identify the abrupt change of runoff. The fluctuation of each factor was evaluated by the variation coefficient, calculated according to the following equation:

$$
C_{\mathrm{v}}=\sigma / \bar{D}
$$

where $\sigma$ and $\bar{D}$ are the standard deviation and average of time series records, respectively.

\subsubsection{Attribution Analysis of Runoff Change}

For a closed watershed, the water balance equation at the multi-year scale can be expressed as follows:

$$
R=P-E T_{a}-\Delta S
$$

where $R$ is the runoff $(\mathrm{mm}), P$ is the precipitation $(\mathrm{mm}), E T_{a}$ is the actual evapotranspiration $(\mathrm{mm}), \Delta S$ is the change in soil water storage $(\mathrm{mm})$. The variation of soil water storage can be considered constant over a long-time scale (more than 10 years), so Equation (3) can be simplified into the following equation:

$$
R=P-E T_{a}
$$

The Budyko hypothesis holds that, there is a coupling equilibrium between water and heat in a watershed under certain climate and vegetation conditions [34]. The relationship between annual mean precipitation, $E T_{0}$ and $E T_{a}$ can be described by an empirical curve. The $E T_{a}$ over a long-time scale can be estimated by the Budyko models. Among them, the Choudhury-Yang [27] model (as follows), obtained through empirical or analytical methods, was widely used with better application effect.

$$
E T_{a}=\frac{P \times E T_{0}}{\left(P^{n}+E T_{0}\right)^{1 / n}}
$$

where $n$ is the parameter reflecting the characteristics of the underlying surface, including landform, soil, and vegetation. The landform, soil, and other factors in the study area did not change significantly during the study period. Therefore, the parameter $n$ was mainly determined by land-use/vegetation cover change and can be calculated by 
Equations (4) and (5). It is generally believed that the increase of $n$ was caused by the improvement of vegetation cover in the basin.

The elasticity coefficient refers to the sensitivity of the dependent variable to independent variable [35]. The elasticity of runoff regarding potential factors can be expressed by the following equation:

$$
E_{x}=\lim _{\Delta x / x \rightarrow 0}\left[\frac{\Delta R / R}{\Delta x / x}\right]=\frac{\partial R}{\partial x} \times \frac{x}{R}
$$

where $R$ is the runoff ( $\mathrm{mm}$ ) and $x$ is a factor (such as precipitation, $E T_{0}$ or vegetation) that can influence the runoff. A positive (negative) elasticity coefficient of the $x$ factor suggests that an increase (decrease) in the $x$ variable will cause an increase (decrease) in runoff. The greater the absolute value of the elasticity coefficient, the higher the sensitivity.

Combining Equations (4)-(6), we can derive:

$$
\begin{aligned}
\Delta R & =\frac{\partial f}{\partial P} d P+\frac{\partial f}{\partial E T_{0}} d E T_{0}+\frac{\partial f}{\partial n} d n \\
& =\left[\frac{\partial R}{\partial P} \frac{P}{R}\right] \frac{\Delta P}{P} R+\left[\frac{\partial R}{\partial E T_{0}} \frac{E T_{0}}{R}\right] \frac{\Delta E T_{0}}{E T_{0}} R+\left[\frac{\partial R}{\partial n} \frac{n}{R}\right] \frac{\Delta n}{n} R+\delta \\
& =\varepsilon_{P} \frac{\Delta P}{P} R+\varepsilon_{E T_{0}} \frac{\Delta E T_{0}}{E T_{0}} R+\varepsilon_{n} \frac{\Delta n}{n} R+\delta \\
& =C_{P}+C_{E T_{0}}+C_{n}+\delta
\end{aligned}
$$

where $C_{P}, C_{E T_{0}}$, and $C_{n}$ make up the contribution of precipitation, $E T_{0}$ and $n$ to the change of runoff, respectively, $\varepsilon_{P}, \varepsilon_{E T_{0}}$, and $\varepsilon_{n}$ make up the elasticity of runoff to precipitation, $E T_{0}$ and $n$, respectively, $\delta$ is the systematic error.

\section{Results}

\subsection{Identification of Abrupt Change in Runoff}

The result of the MK method showed that the $U F(k)$ and $U B(k)$ statistical curves generated for runoff had an intersection in 2000 (Figure 2a). The intersection was within the critical value $(\alpha=0.05, \mathrm{Y}= \pm 1.96)$, indicating that the temporal sequence abruptly changed in 2000.

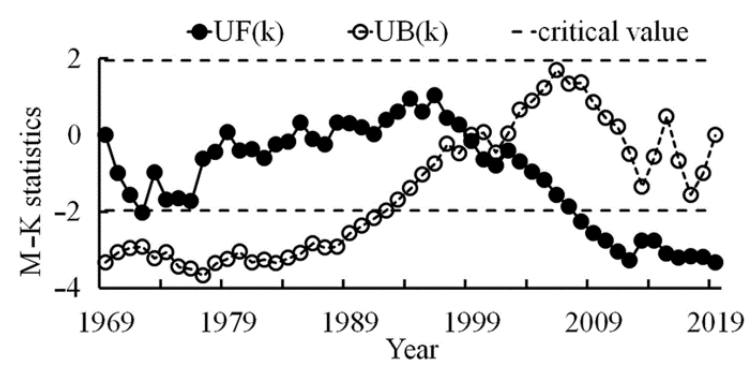

(a)

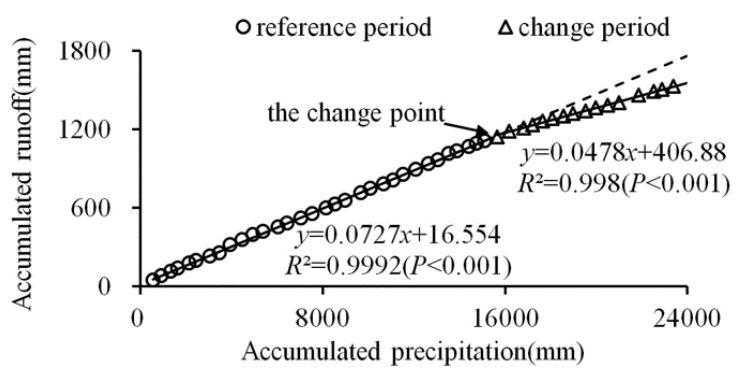

(b)

Figure 2. Analysis of runoff abrupt change: (a) MK mutation test, (b) double mass curves of precipitation-runoff.

Based on the result of MK analysis, the study period was divided into a reference period (1969-2000, $\mathrm{P}_{\mathrm{I}}$ ) and a change period (2001-2019, $\left.\mathrm{P}_{\mathrm{II}}\right)$, then a double mass curve was performed on the precipitation-runoff (Figure $2 \mathrm{~b}$ ). As shown, the correlations $\left(R^{2}\right)$ of the fitted trend line of the above cumulative quantities were all relatively high $(p<0.001)$ whether during $\mathrm{P}_{\mathrm{I}}$ or $\mathrm{P}_{\mathrm{II}}$. The slope of the fitting curve changed significantly in 2000 , which was consistent with the conclusion of the MK method.

\subsection{Inter-Annual Alteration in Hydrological and Meteorological Elements}

Annual hydrological and meteorological records indicated that the observed runoff (Figure 3a) significantly decreased $\left(p<0.05,-0.2845 \mathrm{~mm}\right.$ year ${ }^{-1}$ ) from 1969 to 2019 , while the $E T_{0}$ (Figure $\left.3 b\right)$ exhibited an insignificant upward trend $\left(p<0.001,4.6696 \mathrm{~mm}\right.$ year $\left.^{-1}\right)$. The 
precipitation (Figure 3c) also showed an overall upward trend $\left(p>0.05,1.3795 \mathrm{~mm} \mathrm{year}^{-1}\right)$, but only $3.48 \%$ of the total variance can be explained by the timing of the measurement.

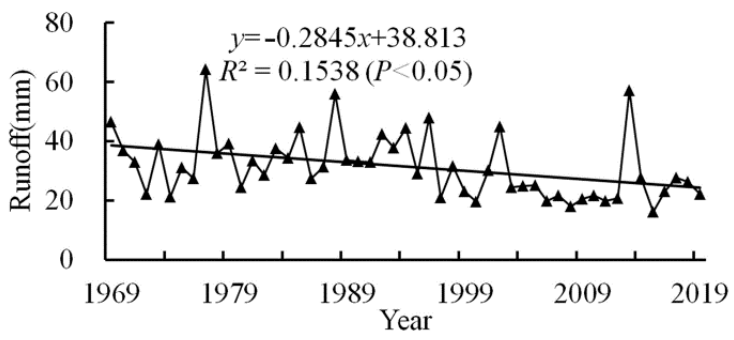

(a)

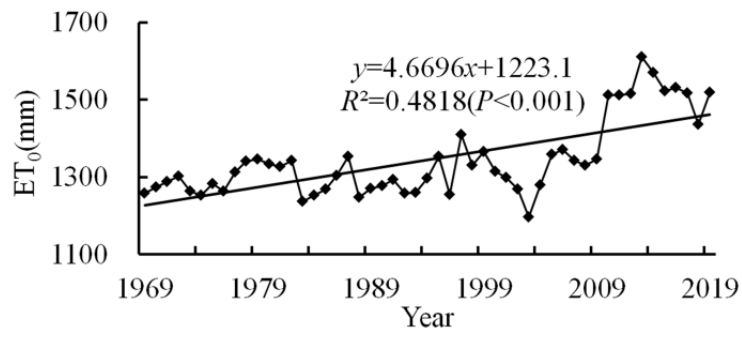

(b)

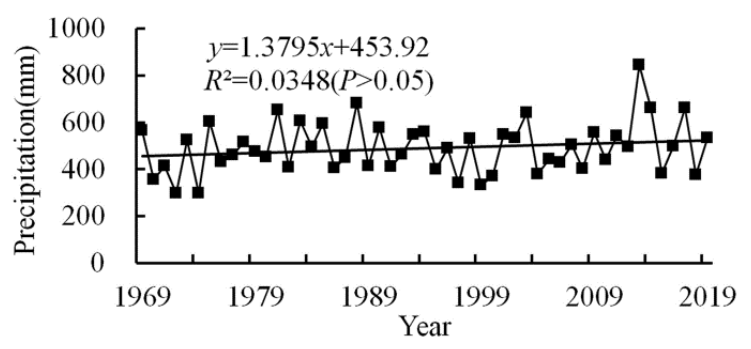

(c)

Figure 3. Evolution law of hydrological and meteorological elements: (a) runoff; (b) $E T_{0}$; (c) precipitation.

The different performance of hydrological and meteorological elements in $\mathrm{P}_{\mathrm{I}}$ and $\mathrm{P}_{\mathrm{II}}$ are shown in Figure 4. The precipitation increased from $472.27 \mathrm{~mm}\left(\mathrm{P}_{\mathrm{I}}\right)$ to $519.30 \mathrm{~mm}$ $\left(\mathrm{P}_{\mathrm{II}}\right)$, with a relative change rate of $9.96 \%$ (Figure $4 \mathrm{a}$ ). The variation range of precipitation narrowed in $\mathrm{P}_{\mathrm{II}}$, but the data points were denser away from the median and there were outliers deviating greatly from the box, indicating the frequency of extreme precipitation. The $E T_{0}$ increased from $1298.07 \mathrm{~mm}\left(\mathrm{P}_{\mathrm{I}}\right)$ to $1422.79 \mathrm{~mm}\left(\mathrm{P}_{\mathrm{II}}\right)$, with a relative change rate of $9.61 \%$ (Figure $4 \mathrm{~b}$ ). The variation range of $E T_{0}$ expanded considerably in $\mathrm{P}_{\mathrm{II}}$, almost all data points were distributed away from the median, close to the extrema. This suggested that the $E T_{0}$ fluctuated greatly during $\mathrm{P}_{\mathrm{II}}$, which may be related to the surface disturbance caused by the GGP.

Compared with $\mathrm{P}_{\mathrm{I}}$, the runoff in $\mathrm{P}_{\mathrm{II}}$ decreased by $8.82 \mathrm{~mm}$, with a relative change of $-25.42 \%$ (Figure 4c). Especially in the early 21st century (2000-2009), the average runoff decreased to $24.90 \mathrm{~mm}, 28.24 \%$ lower than that before 2000, while the decline trend has slowed down since 2010. The variation range of runoff narrowed significantly during $\mathrm{P}_{\mathrm{II}}$, but there were many outliers far away from the box, which was considered to be related to the occurrence of extreme precipitation events.

The statistics of the intergenerational level changes of each element (Table 1) showed that the variation coefficient of runoff and precipitation both initially decreased before subsequently increasing, reaching their maximum between 2010 and 2019. The variation coefficient of $E T_{0}$ experienced a gradual increase and then decreased slightly, with a maximum between 1990 and 2010. 


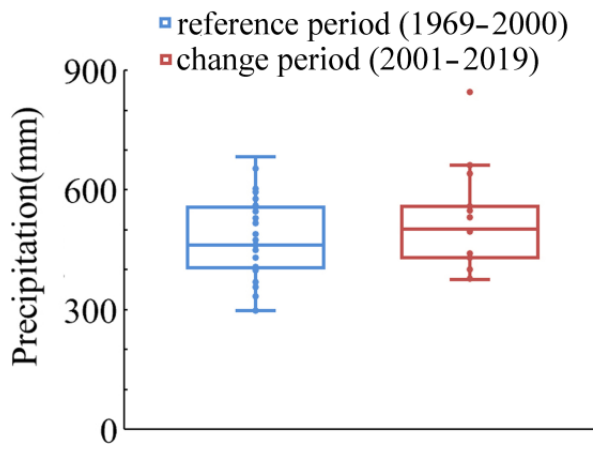

(a)

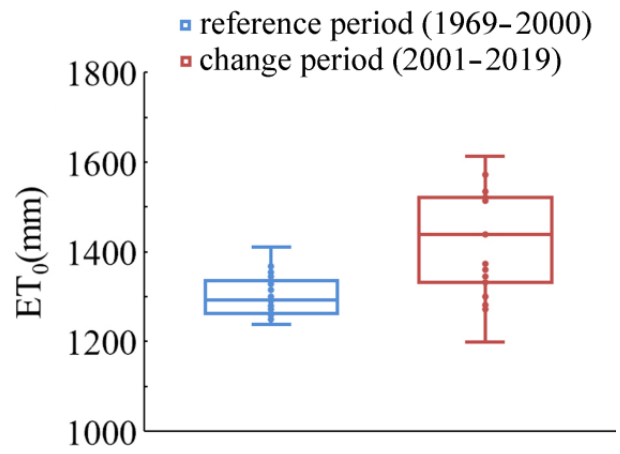

(b)

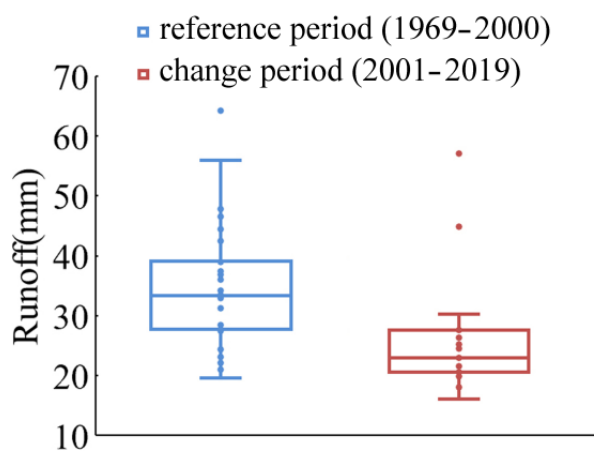

(c)

Figure 4. Characteristics of hydrological and meteorological elements during reference period and change period: (a) precipitation; (b) $E T_{0}$; (c) runoff.

Table 1. The variation coefficient of hydrological and meteorological elements in the past 50 years.

\begin{tabular}{cccc}
\hline Period & Runoff & Precipitation & $\boldsymbol{E T}_{\mathbf{0}}$ \\
\hline $1969-1979$ & 0.318 & 0.217 & 0.024 \\
$1980-1989$ & 0.250 & 0.198 & 0.032 \\
$1990-1999$ & 0.245 & 0.184 & 0.038 \\
$2000-2009$ & 0.300 & 0.177 & 0.038 \\
$2010-2019$ & 0.414 & 0.253 & 0.028 \\
$1969-2019$ & 0.340 & 0.074 & 0.222 \\
\hline
\end{tabular}

\subsection{Elasticity of Runoff to Climate and Vegetation}

As shown in Table 2, during the whole study period (1969-2019), the elasticity coefficient of runoff to precipitation and $E T_{0}$ were 0.166 and -0.039 , respectively. This indicates that, when precipitation or $E T_{0}$ increased by $10 \%$, runoff would increase by $1.66 \%$ or decrease by $0.39 \%$, respectively, and vice versa. The elasticity coefficient of runoff to the underlying surface parameter $n$, which represented vegetation change, was -1.738 , indicating that runoff would be decreased by $17.38 \%$ when vegetation coverage increased by $10 \%$.

Parameter $n$ increased from $1.896\left(\mathrm{P}_{\mathrm{I}}\right)$ to $2.244\left(\mathrm{P}_{\mathrm{II}}\right)$, with a relative increase of $17.3 \%$, indicating that the vegetation condition experienced a profound change during $\mathrm{P}_{\mathrm{II}}$. The elasticity coefficients of runoff to precipitation and $E T_{0}$ changed from $0.189\left(\mathrm{P}_{\mathrm{I}}\right)$ to $0.133\left(\mathrm{P}_{\mathrm{II}}\right)$, and $-0.043\left(\mathrm{P}_{\mathrm{I}}\right)$ to $-0.033\left(\mathrm{P}_{\mathrm{II}}\right)$, respectively, indicating that the effect of precipitation and $E T_{0}$ on runoff has weakened in the 21st century. Overall, the sensitivity of runoff to precipitation, $E T_{0}$, and underlying surface conditions all decreased during the change period. 
Table 2. The elasticity of runoff regarding each factor in different periods.

\begin{tabular}{ccccc}
\hline Period & $n$ & $\boldsymbol{\varepsilon}_{\boldsymbol{P}}$ & $\boldsymbol{\varepsilon}_{\boldsymbol{E} \boldsymbol{T}_{\mathbf{0}}}$ & $\boldsymbol{\varepsilon}_{\boldsymbol{n}}$ \\
\hline Reference period $\left(\mathrm{P}_{\mathrm{I}}, 1969-2000\right)$ & 1.896 & 0.189 & -0.043 & -2.033 \\
Change period $\left(\mathrm{P}_{\mathrm{II}}, 2001-2019\right)$ & 2.244 & 0.133 & -0.033 & -1.339 \\
Study period $(1969-2019)$ & 2.025 & 0.166 & -0.039 & -1.738 \\
\hline
\end{tabular}

\subsection{Composition and Transfer of Land-Use}

According to the interpretation results (Figure 5) of remote sensing images in 1985, 1995, 2008, 2010, and 2015, the area proportions of each land-use type in the Yanhe River basin were calculated. The area of farmland, woodland, and grassland accounted for $99.29 \%$, $99.22 \%, 99.16 \%, 99.05 \%$, and $95.91 \%$, respectively, of the total area in the years above.
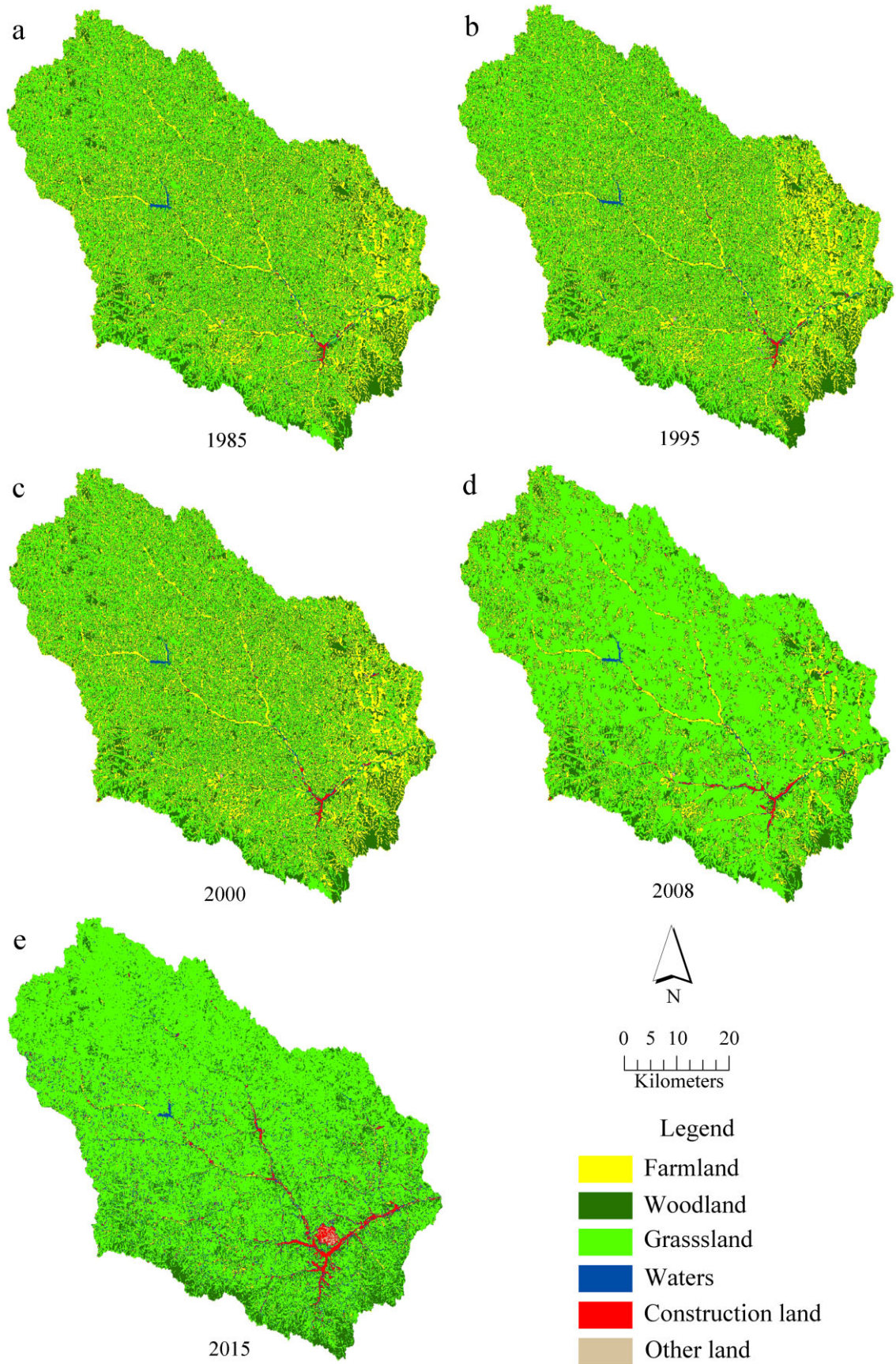

Figure 5. Composition of land-use from 1985 to 2015: (a) 1985; (b) 1995; (c) 2000; (d) 2008; (e) 2015. 
The land-use transfer matrix (Table 3) was constructed based on the spatial analysis toolbox of ArcGIS. It can be found that agriculture was the main mode of production in the study area in 1985-2000, with slow transfer among different land-use types. Since 2000 , the balance of original land-use structure fundamentally changed, and the obvious transfer among farmland, woodland, and grassland was the dominant process during this period. The area of farmland in 2015 decreased by $2259.11 \mathrm{~km}^{2}(88.07 \%)$ compared with 2000 , of which $161.24 \mathrm{~km}^{2}$ and $2010.58 \mathrm{~km}^{2}$ were converted to woodland and grassland, respectively. The area proportion of woodland and grassland increased to $91 \%$ of the total area, caused by the implementation of the GGP. The increase of grassland and woodland has greatly altered the underlying surface, effectively improving the capacity of the soil to conserve water and maintain a low level of runoff in the watershed.

Table 3. Land-use transfer matrix from 1985 to $2015\left(\mathrm{~km}^{2}\right)$.

\begin{tabular}{|c|c|c|c|c|c|c|c|}
\hline Period & Land-Use & Farmland & Construction Land & Other Land & Woodland & Grassland & Waters \\
\hline \multirow{6}{*}{ 1985-1995 } & Farmland & 2513.95 & 2.72 & 0.1 & 13.04 & 33.95 & 1.33 \\
\hline & Construction land & 0.1 & 22.18 & 0 & 0 & 0.1 & 0.05 \\
\hline & Other land & 0 & 0 & 2.5 & 0 & 0 & 0 \\
\hline & Woodland & 14.94 & 0.38 & 0 & 498.69 & 40.84 & 0.07 \\
\hline & Grassland & 57.83 & 0.17 & 0 & 18.93 & 2652.82 & 0.47 \\
\hline & Waters & 0.23 & 0 & 0 & 0.15 & 0.32 & 15.78 \\
\hline \multirow{6}{*}{ 1995-2000 } & Farmland & 2359.47 & 4.05 & 0.53 & 42.67 & 177.91 & 2.42 \\
\hline & Construction land & 2.09 & 22.08 & 0 & 0.4 & 0.79 & 0.09 \\
\hline & Other land & 0.75 & 0 & 1.75 & 0.01 & 0.09 & 0 \\
\hline & Woodland & 24.93 & 0.33 & 0.01 & 479.7 & 25.6 & 0.24 \\
\hline & Grassland & 156.96 & 1.79 & 0.04 & 47.72 & 2520.54 & 0.98 \\
\hline & Waters & 1.75 & 0.15 & 0.03 & 0.13 & 0.75 & 14.89 \\
\hline \multirow{6}{*}{ 2000-2008 } & Farmland & 1023.16 & 8.13 & 0 & 75.28 & 1438.6 & 0.78 \\
\hline & Construction land & 2.56 & 25.37 & 0 & 0.21 & 0.21 & 0.05 \\
\hline & Other land & 0.13 & 0.17 & 2.06 & 0 & 0 & 0 \\
\hline & Woodland & 0 & 0.26 & 0 & 570.37 & 0 & 0 \\
\hline & Grassland & 0 & 0.76 & 0 & 0 & 2724.45 & 0.47 \\
\hline & Waters & 0.8 & 0.86 & 0 & 0.03 & 0.02 & 16.91 \\
\hline \multirow{6}{*}{ 2008-2015 } & Farmland & 295.23 & 51.66 & 18.44 & 85.96 & 571.98 & 3.38 \\
\hline & Construction land & 0.54 & 30.7 & 0.15 & 0.43 & 3.62 & 0.11 \\
\hline & Other land & 0.01 & 0.03 & 0.04 & 0.18 & 1.8 & 0 \\
\hline & Woodland & 1.13 & 8.54 & 4.33 & 437.39 & 193.81 & 0.69 \\
\hline & Grassland & 8.95 & 68.25 & 38.08 & 753.17 & 3287.44 & 7.39 \\
\hline & Waters & 0.12 & 4 & 0.32 & 0.53 & 8.33 & 4.91 \\
\hline
\end{tabular}

\subsection{Attribution Analysis of Runoff Change}

The contribution of precipitation, $E T_{0}$, and vegetation to runoff change can be obtained by Equation (7), and the results are shown in Table 4 . Since runoff was positively correlated with precipitation change, the upward trend of precipitation during $\mathrm{P}_{\mathrm{II}}$ did not contribute to the decrease of runoff. On the contrary, precipitation increased runoff by $0.461 \mathrm{~mm}$ with a contribution of $-5.23 \%$. The contribution of $E T_{0}$ was $6.15 \%$, which reduced runoff by $0.542 \mathrm{~mm}$ during the whole study period.

Table 4. Contribution of hydrological and meteorological elements to runoff change.

\begin{tabular}{ccccc}
\hline & $C_{\boldsymbol{P}}$ & $C_{\boldsymbol{E} \boldsymbol{T}_{\boldsymbol{0}}}$ & $\boldsymbol{C}_{\boldsymbol{n}}$ & $\delta$ \\
\hline Variation $/ \mathrm{mm}$ & 0.461 & -0.542 & -8.536 & -0.203 \\
Contribution $/ \%$ & -5.23 & 6.15 & 96.78 & 2.30 \\
\hline
\end{tabular}

On the whole, the vegetation contributed the most of runoff decline, reaching $96.78 \%$, and the corresponding runoff variation was $-8.536 \mathrm{~mm}$. The change of underlying surface 
conditions caused by vegetation restoration resulted in a significant decrease of runoff and offset the effect of precipitation increase.

In addition, we noticed that the systematic error was only $2.30 \%$ in the process of attribution analysis, indicating that the elasticity coefficient method was feasible for application in the typical arid/semi-arid region. However, at the same time, it also suggested that there were still one or more unknown factors affecting the change of runoff, besides precipitation, $E T_{0}$ and vegetation.

\section{Discussion}

\subsection{Variation of Hydrological and Meteorological Elements in the Yanhe River Basin}

Ren et al. [36] found that with the reduction in precipitation, runoff and sediment load in the Yanhe River basin declined between 1961 and 2008. Li et al. [37] reached a similar conclusion by analyzing hydrological records in the Yanhe River basin between 1952 and 2003. Our study found that the decline in runoff $(p<0.05)$ became more significant as the study period was expanded from 1969 to 2019. Additional temporal data, however, showed that the change of precipitation turned into an insignificant upward trend. This finding about precipitation is different from the research conclusions of other scholars. With the $E T_{0}$ also showing an extremely significant upward trend $(p<0.001)$, we suggest that the hydrological and meteorological situation within the Yanhe River basin has changed during the past 10 years, and there are also signs of warming-wetting.

The precipitation data points were highly discrete and far away from the median during $\mathrm{P}_{\mathrm{II}}$, accompanied by outliers, and the variation coefficient reached its maximum in 2010-2019. All this indicates that, since the 21st century, especially the past 10 years, precipitation has experienced severe fluctuation, with more extreme precipitation events. The variation coefficient of runoff also showed the maximum in 2010-2019, which may have resulted from the extreme precipitation events and long-term accumulation of the GGP.

\subsection{Attribution Analysis of Runoff Change}

The obvious decrease of runoff in the Loess Plateau has been widely reported, but the dominant factors causing the change have been different in different periods. Zhang et al. [38] analyzed the runoff change and its leading factors in 11 basins of the Loess Plateau since the 1950s and concluded that the change of land use/cover caused by anthropogenic disturbance contributed more than $50 \%$ of the runoff reduction in eight basins, and climate factors played a more important role in the remaining three basins. Since the 21st century, it has been recognized that anthropogenic disturbance, represented by ecological restoration measures, have significantly reduced runoff in the Yanhe River basin. However, due to different research periods and methods, the contribution of anthropogenic disturbance has not exactly been the same. Gao et al. [39] believed that the contribution of climate factor to runoff change in the Yanhe River basin was almost equal to that of anthropogenic disturbance, while Wang et al. [40] concluded that the contribution of anthropogenic disturbance was much higher than that of climate factor, reaching $77.4 \%$. We also consider that the change of underlying surface conditions caused by anthropogenic disturbance was the leading factor of runoff reduction in the Yanhe River basin, but its contribution was more than 95\%, which is different from previous studies. At the same time, we also found that the frequent occurrence of extreme climate in the last five years has led to a certain recovery of runoff in the basin with time, which has not been reported yet. Whether this trend can continue in the future needs to be tested by more measured data of longer time series.

\subsection{The Eco-Hydrological Effects of Vegetation Restoration}

In recent years, some scholars have carried out a series of studies on vegetation change and its eco-hydrological effect. Since the 1980s, a significant greening trend has been observed over $25 \%$ to $50 \%$ of the global area, which has changed the process of the global surface water cycle [41]. The vegetation coverage in China has been also improved 
significantly since 2000, due to the impact of climate change and human activities [42]. The vegetation restoration projects have reduced sediment loads (about 90\%) and measured runoff in the LP, resulting in an obvious decrease in the runoff coefficient in the middle reaches of the YR. Some scholars suggested that the vegetation restoration should be slowed down, otherwise it will lead to regional shortage of food and water resources.

In order to analyze the impact of the GGP on the eco-hydrological effect of vegetation, the $\mathrm{P}_{\mathrm{II}}$ was further divided into two periods (2001-2009 and 2010-2019) with a 10-year cycle to compare parameter $n$ and its corresponding elasticity coefficient. The parameter $n$ decreased in the 2010s, compared with that in 2001-2009 (Table 5), and the sensitivity of runoff to vegetation coverage has been reduced since the 2010s. It can be concluded that, although the area of woodland and grassland has still increased since 2010, it may not achieve the expected effect of vegetation restoration. Xia et al. [43] compared the underlying surface parameters and vegetation coverage in the Yanhe River basin from 2002 to 2016 by using the equation derived from the Budyko hypothesis. They found that the increasing trend of vegetation coverage has slowed significantly since 2010, which was not synchronized with the increase in woodland and grassland area, and the underlying surface parameters obviously showed the same performance. This opinion coincides with the conclusion of this article. In the initial stage, the vegetation restoration measures have a sharp impact on runoff, but with the vegetation restoration reaching a stable period, the impact may tend to moderate. The long-term effects of vegetation restoration on runoff need to be further studied.

Table 5. The change of parameter $n$ and elasticity during the change period.

\begin{tabular}{ccc}
\hline Period & $\boldsymbol{n}$ & $\boldsymbol{\varepsilon}_{\boldsymbol{n}}$ \\
\hline $2001-2009$ & 2.271 & -1.398 \\
$2010-2019$ & 2.224 & -1.215 \\
\hline
\end{tabular}

The GGP would theoretically increase the vegetation coverage, but the planted trees may consume more water, while the poor water resources in arid/semi-arid areas of the LP may aggravate the water shortage in a short period, thus adversely affecting the vegetation diversity. Cao et al. [44] took five demonstration counties as examples in northern Shaanxi Province to study the influence of the GGP on vegetation coverage, and the results showed that the GGP resulted in a $30.5 \%$ decrease within vegetation coverage in afforestation areas. Improper selection of tree species or high planting density was considered to be the main cause of the negative effects above. How to increase the survival rate of afforestation is also the focus of further research.

\subsection{Uncertainty in Attribution Analysis of Runoff Change}

The original study from Budyko did not consider the factors such as underlying surface and watershed area, so the evapotranspiration rate and drought index calculated from measured data could not be fully projected on the Budyko curve in accordance with ideal conditions but were scattered around the curve. The method of interpreting these discrete points is mainly reflected by the control parameters in a series of empirical equations. In this paper, we applied the Choudhury-Yang coupling equation in the Yanhe River basin located in the Loess hilly-gully region, but there might still be some uncertainties resulting in systematic error.

In the process of calculating the contribution of the potential factor, the systematic error was $2.3 \%$, indicating that the uncertainty has a limited influence on the final conclusion. The changes in runoff documented in this study would not be detectable in many humid regions having abundant vegetation, so the approach is likely to be applicable to basins in other arid/semi-arid regions which are sensitive to short-term (decadal scale) climatic shifts. 


\section{Conclusions}

The Chinese government has implemented a number of ecological conservation and protection projects in arid/semi-arid regions to control soil erosion. In this paper, the Yanhe River basin was selected as the study area. We analyzed the variation trends of major measured hydrology and meteorology elements and identified the factors influencing runoff with the elasticity coefficient method based on the Budyko hypothesis. The results showed the following: (1) Between 1969 and 2019, the measured runoff showed an obvious downward trend ( $p<0.05$ ), with an abrupt change in 2000, and the average runoff in the change period decreased by $25.42 \%$ compared with that in the reference period. Precipitation and $E T_{0}$ showed an upward trend $(p>0.05)$ and a significant decreasing trend $(p<0.001)$, respectively. The climate condition showed a trend of warming-wetting. (2) Farmland, woodland, and grassland were the three main land-use types, accounting for more than $95 \%$ in total. Due to the GGP, the proportion of woodland and grassland has gradually increased to $91 \%$ since the 21 st century, compared with that in 2000 . (3) The underlying surface parameter $n$ increased from 1.896 in the reference period to 2.244 in the change period, with a relative increase of $18.35 \%$. The vegetation was the leading factor resulting in the decline of runoff with a contribution of $96.78 \%$, while the $E T_{0}$ followed with a contribution of $6.15 \%$. Precipitation increased runoff with a contribution of $5.23 \%$. (4) By analyzing the periodic change of parameter $n$ and the elasticity coefficient, we suggest that the response of runoff to vegetation restoration measures has a certain threshold effect in an arid/semi-arid area, and the runoff reduction will not remain for a long time. It may be related to the short-term water shortage caused by large-scale vegetation restoration, thus affecting the survival rate of afforestation. Large-scale vegetation restoration needs to be carried out carefully under the premise of assessing a reasonable threshold to avoid an ecological disaster.

Author Contributions: Data curation, J.W.; Methodology, X.W.; Writing-original draft, K.H.; Writing-review and editing, X.W. All authors have read and agreed to the published version of the manuscript.

Funding: This research was funded by [Natural Science Foundation of China] grant number [41871195]. And The APC was also funded by the funder above.

Data Availability Statement: The data used in this study are available from the corresponding author on reasonable request.

Acknowledgments: We thank the two anonymous reviewers for their valuable comments and constructive suggestions on the manuscript.

Conflicts of Interest: The authors declare no conflict of interest.

\section{References}

1. Piao, S.; Ciais, P.; Huang, Y.; Shen, Z.; Peng, S.; Li, J.; Zhou, L.; Liu, H.; Ma, Y.; Ding, Y.; et al. The impacts of climate change on water resources and agriculture in China. Nature 2010, 467, 43-51. [CrossRef] [PubMed]

2. Wang, S.; Fu, B.; Piao, S.; Lü, Y.; Ciais, P.; Feng, X.; Wang, Y. Reduced sediment transport in the Yellow River due to anthropogenic changes. Nat. Geosci. 2016, 9, 38-41. [CrossRef]

3. Nilsson, C.; Reidy, C.A.; Dynesius, M.; Revenga, C. Fragmentation and flow regulation of the world's large river systems. Science 2005, 308, 405-408. [CrossRef] [PubMed]

4. Li, Y.; Liu, C.; Zhang, D.; Liang, K.; Li, X.; Dong, G. Reduced runoff due to anthropogenic intervention in the Loess Plateau, China. Water 2016, 8, 458. [CrossRef]

5. Yao, W.; Xiao, P.; Shen, Z.; Wang, J.; Jiao, P. Analysis of the contribution of multiple factors to the recent decrease in load and sediment yield in the Yellow River basin, China. J. Geogr. Sci. 2016, 26, 1289-1304. [CrossRef]

6. Milly, P.C.D.; Betancourt, J.; Falkenmark, M.; Hirsch, R.; Kundzewicz, Z.; Lettenmaier, D.; Stouffer, R. Stationarity is dead: Whither water management? Science 2008, 319, 573-574. [CrossRef]

7. Jaramillo, F.; Destouni, G. Local flow regulation and irrigation raise global human water consumption and footprint. Science 2015, 350, 1248-1251. [CrossRef]

8. Song, X.; Zhang, J.; Zhan, C.; Liu, C. Review for impacts of climate change and human activities on water cycle. J. Hydraul. Eng. 2013, 44, 779-790. (In Chinese) [CrossRef] 
9. Zhang, X.; Zheng, J.; Hao, Z. Climate change assessments for the main economic zones of China during recent decades. Prog. Geogr. 2020, 39, 1609-1618. (In Chinese) [CrossRef]

10. Li, M.; Sun, H.; Su, Z. Research progress in dry/wet climate variation in Northwest China. Geogr. Res. 2021, 40, 1180-1194. (In Chinese) [CrossRef]

11. Liu, C.; Wang, P.; Wen, T.; Yu, D.; Bai, W. Spatio-temporal characteristics of climate change in the Yellow River source area from 1960 to 2019. Arid Zone Res. 2021, 38, 293-302. (In Chinese) [CrossRef]

12. $\mathrm{Gu}, \mathrm{C} . ; \mathrm{Mu}, \mathrm{X} . ; \mathrm{Gao}, \mathrm{P}$; Sun, W.; Zhao, G. Characteristics of temporal variation in precipitation and temperature in the Loess Plateau from 1961 to 2014. J. Arid Land Resour. Environ. 2017, 31, 136-143. (In Chinese) [CrossRef]

13. Ding, Y.; Liu, S.; Li, J.; Shangguan, D. The retreat of glaciers in response to recent climate warming in western China. Ann. Glaciol. 2006, 43, 97-105. [CrossRef]

14. Kingsford, R.T. Ecological impacts of dams, water diversions and river management on floodplain wetlands in Australia. Austral Ecol. 2000, 25, 109-127. [CrossRef]

15. Li, Z.; Liu, X.; Niu, T.; Kejia, D.; Zhou, Q.; Ma, T.; Gao, Y. Ecological restoration and its effects on a regional climate: The source region of the Yellow River, China. Environ. Sci. Technol. 2015, 49, 5897-5904. [CrossRef]

16. Jiang, W.; Yuan, L.; Wang, W.; Cao, R.; Zhang, Y.; Shen, W. Spatio-temporal analysis of vegetation variation in the Yellow River Basin. Ecol. Indic. 2015, 51, 117-126. [CrossRef]

17. Gao, P.; Mu, X.; Wang, F.; Li, R. Changes in streamflow and sediment discharge and the response to human activities in the middle reaches of the Yellow River. Hydrol. Earth Syst. Sci. 2011, 15, 1-10. [CrossRef]

18. $\mathrm{Mu}, \mathrm{X} . ; \mathrm{Zhang}$, L.; Mcvicar, T.; Chille, B.; Gau, P. Analysis of the impact of conservation measures on stream flow regime in catchments of the Loess Plateau, China. Hydrol. Process. 2010, 21, 2124-2134. [CrossRef]

19. Chen, P.; Shang, J.; Qian, B.; Jing, Q.; Liu, J. A New Regionalization Scheme for Effective Ecological Restoration on the Loess Plateau in China. Remote Sens. 2017, 9, 1323. [CrossRef]

20. Mo, K.; Chen, Q.; Chen, C.; Zhang, J.; Wang, L.; Bao, Z. Spatiotemporal variation of correlation between vegetation cover and precipitation in an arid mountain-oasis river basin in northwest China. J. Hydrol. 2019, 574, 138-147. [CrossRef]

21. Li, C.; Wang, J.; Hu, R.; Shan, Y.; Ayal, D. Relationship between vegetation change and extreme climate indices on the Inner Mongolia Plateau, China, from 1982 to 2013. Ecol. Indic. 2018, 89, 101-109. [CrossRef]

22. Sun, W.; Song, X.; Mu, X.; Gao, P.; Wang, F.; Zhao, G. Spatiotemporal vegetation cover variations associated with climate change and ecological restoration in the Loess Plateau. Agric. For. Meteorol. 2015, 209-210, 87-99. [CrossRef]

23. Chang, J.; Wang, Y.; Istanbulluoglu, E.; Bai, T.; Huang, Q.; Yang, D.; Huang, S. Impact of climate change and human activities on runoff in the Weihe River Basin, China. Quat. Int. 2015, 380, 169-179. [CrossRef]

24. Wang, D.; Hejazi, M. Quantifying the relative contribution of the climate and direct human impacts on mean annual streamflow in the contiguous United States. Water Resour. Res. 2011, 47, W00J02. [CrossRef]

25. Brown, A.E.; Lu, Z.; Mcmahon, T.A.; Western, A.W.; Vertessy, R.A. A review of paired catchment studies for determining changes in water yield resulting from alterations in vegetation. J. Hydrol. 2005, 310, 28-61. [CrossRef]

26. Pike, J.G. The estimation of annual run-off from meteorological data in a tropical climate. J. Hydrol. 1964, 2, 116-123. [CrossRef]

27. Yang, H.; Yang, D.; Lei, Z.; Sun, F. New analytical derivation of the mean annual water-energy balance equation. Water Resour. Res. 2008, 44, 893-897. [CrossRef]

28. Zhou, G.; Wei, X.; Chen, X.; Zhou, P.; Liu, X.; Xiao, Y.; Sun, G.; Scott, D.; Zhou, S.; Han, L.; et al. Global pattern for the effect of climate and land cover on water yield. Nat. Commun. 2015, 6, 5918. [CrossRef]

29. Zheng, H.; Zhang, L.; Zhu, R.; Liu, C.; Sato, Y.; Fukushima, Y. Responses of streamflow to climate and land surface change in the headwaters of the Yellow River basin. Water Resour. Res. 2009, 45, 641-648. [CrossRef]

30. Liu, X.; Liu, C.; Luo, Y.; Zhang, M.; Xia, J. Dramatic decrease in streamflow from the headwater source in the central route of China's water diversion project: Climatic variation or human influence? J. Geophys. Res. Atmos. 2012, 117, D06113. [CrossRef]

31. Allen, R.G.; Pereira, L.S.; Raes, D.; Smith, M. Crop Evapotranspiration-Guidelines for Computing Crop Water Requirements; FAO Irrigation and Drainage Paper 56; FAO: Roma, Italy, 1998.

32. Mann, H.B. Nonparametric test against trend. Econometrica 1945, 13, 245-259. [CrossRef]

33. Kendall, M.G. Rank correlation methods. Brit. J. Psychol. 1990, 25, 86-91. [CrossRef]

34. Budyko, M.I. Evaporation under Natural Conditions, Gidrometeoizdat, Leningrad 1948; English Translation byIsrael Program for Scientific Translations; IPST: Jerusalem, Israel, 1963.

35. Patterson, L.A.; Lutz, B.; Doyle, M.W. Climate and direct human contributions to changes in mean annual streamflow in the South Atlantic, USA. Water Resour. Res. 2013, 49, 7278-7291. [CrossRef]

36. Ren, Z.; Zhang, G.; Yang, Q. Characteristics of runoff and sediment variation in Yanhe River basin in last 50 years. J. China Hydrol. 2012, 32, 81-86. (In Chinese) [CrossRef]

37. Li, C.; Wang, H.; Yu, F.; Yang, A.; Yan, D. Impact of soil and water conservation on runoff and sediment in Yanhe River Basin. Sci. Soil Water Conserv. 2011, 9, 1-8. (In Chinese) [CrossRef]

38. Zhang, X.; Zhang, L.; Zhao, J.; Rustomji, P.; Hairsine, P. Responses of streamflow to changes in climate and land use/cover in the Loess Plateau, China. Water Resour. Res. 2008, 44, W00A07. [CrossRef]

39. Gao, P.; Jiang, G.; Wei, Y.; Mu, X.; Wang, F.; Zhao, G.; Sun, W. Streamflow regimes of the Yanhe River under climate and land use change, Loess Plateau, China. Hydrol. Process. 2015, 29, 2402-2413. [CrossRef] 
40. Wang, Y.; Feng, Q. Characteristics of runoff and sediment transport during 1960-2010 and its response to Grain for Green Project in Yanhe River. Sci. Soil Water Conserv. 2017, 15, 1-7. (In Chinese) [CrossRef]

41. Zhu, Z.; Piao, S.; Myneni, R.; Huang, M.; Zeng, Z.; Canadell, J.; Ciais, P.; Sitch, S.; Friedlingstein, P.; Arneth, A.; et al. Greening of the earth and its drivers. Nat. Clim. Change 2016, 6, 791-795. [CrossRef]

42. Yang, D.; Shao, W.; Yeh, P.J.F.; Yang, H.; Kanae, S.; Oki, T. Impact of vegetation coverage on regional water balance in the nonhumid regions of China. Water Resour. Res. 2009, 45, 507-519. [CrossRef]

43. Xia, Y.; Zhang, S.; Gao, W.; Zhang, H.; Guo, L. Influence of greening Loess Plateau on streamflow change in Yanhe River basin of the middle Yellow River, China. J. Earth Sci. Environ. 2020, 42, 849-860. (In Chinese) [CrossRef]

44. Cao, S.; Chen, L.; Yu, X. Impact of China's Grain for Green Project on the landscape of vulnerable arid and semi-arid agricultural regions: A case study in northern Shaanxi Province. J. Appl. Ecol. 2009, 46, 536-543. [CrossRef] 